\title{
Validating precipitation forecasts using remote sensor synergy: A case study approach
}

\author{
Monika Pfeifer ${ }^{1,2}$, Wenchieh Yen $^{3}$, Michael Baldauf $^{5}$, GeOrge Craig $^{2}$, Susanne $^{2}$ \\ CREWEll $^{3 *}$, JÜrgen FisCher $^{4}$, MARTIN HAGEN $^{2}$, ANJA HÜHNERBEIN ${ }^{4}$, MARIO MECH $^{3}$, \\ THORSTEN REINHARDT ${ }^{3}$, MARC SCHRÖDER $^{5}$, and AXEL SEIFERT ${ }^{5}$
}

${ }^{1}$ Selex Systems Integration GmbH, Gematronik Weather Radar Systems, Neuss, Germany

${ }^{2}$ DLR Institut für Physik der Atmosphäre, Oberpfaffenhofen, Germany

${ }^{3}$ Institut für Geophysik und Meteorologie, Universität zu Köln, Köln, Germany

${ }^{4}$ Institut für Weltraumwissenschaften, Freie Universität Berlin, Berlin, Germany

${ }^{5}$ Deutscher Wetterdienst (DWD), Offenbach, Germany

(Manuscript received November 30, 2009; in revised form June 16, 2010, accepted June 17, 2010)

\begin{abstract}
Several types of remote sensing data are applied synergistically to evaluate the chain of microphysical processes leading to precipitation in a high-resolution numerical weather prediction model. The data provides information relating to (i) cloud-top temperature and optical depth (SEVERI), (ii) ice cloud amount (AMSUB), (iii) type and amount of precipitation particles (polarimetric radar), and (iv) surface precipitation (raingauge-calibrated radar data). Forecasts are produced by the COSMO-DE model of the German weather service, with a horizontal resolution of $2.8 \mathrm{~km}$. The comparison with data is done in a model-to-observation framework, that is, forward operators are applied to the model output to produce synthetic data sets that can be directly compared to the observations. Additional diagnostics based on diurnal cycle and system tracking are also considered. Two case studies over Germany from the summer of 2006 are examined. The first case is dominated by widespread stratiform precipitation. Together the various data sets show that the model overestimates the amount of high cloud, while underestimating the concentration of ice scatterers and overestimating reflectivity and differential reflectivity (ZDR). This indicates errors in both the amount and the size distributions of cloud and precipitation particles in the model's microphysical parameterization. In the second case a narrow band of convective precipitation is embedded in a cold front, with significant modulation by the diurnal cycle. The model fails to show a significant diurnal cycle in cloud amount, and the timing and duration of convective cells is incorrect. In this case, both the microphysical parameterization, and errors in the interaction of the simulated front with the orography of the Alps appear to contribute. These results demonstrate the potential of combinations of remote sensing data for model evaluation, although a long-term trial will be required to determine whether the errors seen in the case studies are characteristic for COSMO-DE.
\end{abstract}

\section{Zusammenfassung}

Verschiedene Fernerkundungsdaten werden synergetisch zur Evaluierung der mikrophysikalischen Prozesskette der Niederschlagsgenerierung in einem hochaufgelösten numerischen Wettervorhersagemodell genutzt. Die Daten beinhalten Informationen über (i) Wolkenobergrenzentemperatur und optische Dicke (SEVIRI), (ii) Vorkommen von Eis und Schnee (AMSU), (iii) Art und Gehalt an Niederschlagspartikeln (polarimetrisches Radar) und (iv) Bodenniederschlag (Radar mit Niederschlagssammler kalibriert). Die Vorhersagen stammen vom COSMO-DE des Deutschen Wetterdiensts mit einer horizontalen Auflösung von 2,8 km. Der Vergleich wird mittels eines "Modell zu Beobachtung"-Ansatzes durchgeführt, d. h. Vorwärtsoperatoren werden auf den Modelloutput angewendet, um synthetische Beobachtungen zu generieren, die direkt mit den Beobachtungen verglichen werden können. Zusätzliche Diagnostiken basierend auf Tagesgang und Verfolgung einzelner Konvektionszellen werden ebenfalls angewendet. Zwei Fallstudien über Deutschland aus dem Sommer 2006 werden untersucht. Die erste Fallstudie wird von ausgedehntem Niederschlag dominiert. Die verschiedenen Daten zeigen, dass das Modell den Anteil hoher, stratiformer Wolken überschätzt, während die Konzentration größerer streuender Eispartikel unter- und die bodennahe Reflektivität und die differentielle Reflektivität (ZDR) überschätzt werden. Dies deutet auf Fehler in den mikrophysikalischen Parameterisierungen sowie in den Annahmen zur Größenverteilung von Wolken- und Niederschlagspartikeln im Modell hin. In der zweiten Fallstudie ist ein enges Band konvektiven Niederschlages eingebettet in eine Kaltfront, mit signifikanter Modulation durch den Tagesgang. Dem Modell gelingt es nicht einen deutlichen Tagesgang in der Wolkenbedeckung zu reproduzieren und Einsetzen sowie Lebensdauer der konvektiven Zellen werden nicht getroffen. In diesem Fall scheinen sowohl die mikrophysikalischen Parametrisierungen als auch die Wechselwirkung der Front mit der Orographie der Alpen zum Fehler der Vorhersage beizutragen. Diese Resultate zeigen das Potential der Kombination verschiedener Fernerkundungsdaten für die Modellevaluierung. Um zu überprüfen, dass diese Fehler charakteristisch für das COSMO-DE sind, ist jedoch eine langfristige Vergleichsstudie nötig.

*Corresponding author: Susanne Crewell, Institute for Geophysics and Meteorology, University of Cologne, Zülpicher Str. 49a, 50674 Cologne, Germany, e-mail: crewell@ meteo.uni-koeln.de 


\section{Introduction}

Precipitation is the weather element with the highest impact on the perception of forecast quality in the society as it strongly affects daily life. This is not only true regarding spare time activities, but quantitative precipitation forecasts (QPF) are also of major importance to a number of different sectors as agriculture, water management authorities, industry, and authorities related to civil protection and disaster management. Despite this importance, the skill of QPF is known to be quite low compared to other parameters like temperature or wind although meteorological forecasting methods and observing systems have been constantly improved (FRITSCH et al., 1998; EBERT et al., 2003). These difficulties in QPF are due to the complexity of the processes involved in the formation and nature of clouds and precipitation which are, furthermore, highly variable in time and space. Therefore, FRITSCH et al. (1998) stated that QPF constitutes the most important and significant challenge of weather forecasting.

In the last years several meteorological services developed a new generation of mesoscale numerical weather prediction (NWP) models for high resolution now-casting. By including more detailed microphysical parameterizations the representation of clouds and precipitation, and hence QPF should be enhanced. Examples for this new generation of mesoscale NWP models are the US American WRF (Weather Research and Forecasting Model; SKAMAROCK et al., 2008), the French AROME (Application of Research to Operations in MesoscaleE; DUCrocQ et al., 2005), and the COSMO model (COnsortium for Small-scale Modelling-Deutschland; STEPPELER et al., 2003), the former LM (Lokal-Modell), of the German Weather Service (DWD). COSMO-DE has been developed for the very short forecast range (up to $18 \mathrm{~h}$ ) on the mesogamma scale. One major advantage of the fine spatial resolution consists in the ability to describe deep convection explicitly without using a convection parameterization. Consequently, the emphasis of this development lies in the prediction of severe weather events related to deep moist convection leading, e.g., to super- and multi-cell thunderstorms or squall lines. Furthermore, an improvement in the description of processes resulting from interactions with fine scale topography like severe downslope winds or foehn-storms is expected.

To demonstrate and further improve the skill of this novel model generation, new verification procedures are needed, e.g. moving from univariate to multi-variate techniques. Traditional verification of QPF normally uses radar observations for the information of the spatial distribution of precipitation, blended with raingauges for the information on the precipitation amount. However, the precipitation at the ground is the end product of a number of complex and highly variable and interactive processes in the atmosphere. In order to improve model performance regarding QPF, the capability of the models to realistically represent clouds and precipitation, especially regarding microphysical processes, has to be verified. This is important since the processes leading to the formation, removal, and interactions of the different hydrometeor types are of major significance for the intensity and life cycle of convective events. These processes are normally described in NWP models in parameterized form in order to reduce computational costs. Accordingly microphysical parameterization schemes have been identified by a number of studies as a principal source of error, and the formation and distribution of precipitation has been found to depend on the treatment of the ice phase hydrometeors in the model (e.g., Gilmore et al., 2004; COLLE et al., 2005; GALLUS and PfEIFER, 2008).

Because of the difficulties involved in observing cloud and precipitation parameters, the information content of different remote sensing instruments has to be combined to provide a consistent data set for evaluation. The most detailed information including in situ observation can be gathered in field experiments like the IMPROVE experiment (Improvement of Microphysical Parameterization through Observational Verification Experiment; Stoelinga et al., 2003). On the other hand more significant long-term evaluation requires operational data from satellites and ground-based networks. For Central Europe, such a data set has been gathered since 2007 within the General Observation Period (GOP; CREWELL et al., 2008) as part of the priority program SPP 1167 'Quantitative Precipitation Forecasting' (Hense and Wulfmeyer, 2008) of the German Research Foundation. The SPP project QUEST (Quantitative Evaluation of Regional Precipitation Forecasts Using Multi-Dimensional Remote Sensing Observations) aims to develop the basis to systematically evaluate model performance with regard to QPF on the basis of the GOP data set. Specifically, the performance of the COSMO model is assessed by combining all possible information from different remote sensing instruments.

This paper aims to illustrate the QUEST methodology on the basis of two case studies and to prepare the path for future long-term evaluations. In this respect the matching of observations and model forecast presents a major challenge. Sampling problems are peculiar to precipitation and complicated by the widely varying time and space resolutions of the different sensors. Further, the remotely sensed quantities are not directly related to the parameters used in NWP models to represent clouds and precipitation. One approach to reduce these problems lies in the so-called model-to-observation approach, (e.g., Chevallier and BAUER, 2003) where synthetic observables are simulated from model output. The advantages of this approach are that no additional uncertainties are introduced by a retrieval process and that the uncertainty of the direct measurement can be specified much better than a retrieved product. 
The model-to-observation approach also requires accurate forward operators which need to be consistent with model parameterizations. The following operators have been adapted to COSMO-DE: the satellite forward operator SynSat to simulate synthetic satellite images for Meteosat (KEIL et. al., 2006), the microwave forward operator SynSatMic (Synthetic Satellite simulator for the Microwave range; MECH et al., 2007) to model for example AMSU (Advanced Microwave Sounding Unit) observations, and the polarimetric radar forward operator SynPolRad (PFEIFER et al., 2008). Their combined value will be demonstrated for two case studies from summer 2006 featuring a more stratiform (August $3,2006)$ and a more convective precipitation event (August 28, 2006). The cases were selected from the first summer of quasi-operational COSMO-DE forecasts and represent situations where the general synoptic situation was well captured by the model. Therefore we expect that differences to the observations will mainly stem from physics parameterizations rather than large-scale dynamics.

\section{Setup of the evaluation}

\subsection{The forecasting model COSMO-DE}

COSMO-DE is the very-short-range NWP application of the COSMO model (http://www.cosmo-model.org) which is a non-hydrostatic, fully compressible model in advection form. Since April 16, 2007 it is operational at DWD with a horizontal grid spacing of 2.8 $\mathrm{km}$. The same resolution and setup is used in this study. The model uses a two-time-level integration scheme based on the Runge-Kutta-method of third order for the prediction of the three cartesian wind components and the deviations of pressure and temperature from a hydrostatic base state. This allows the use of an upwind advection scheme of fifth order in the horizontal with Courant-numbers up to 1.4 (WICKER and SKAMAROCK, 2002). For the six humidity variables (mass fractions of moisture, cloud and rain water, cloud ice, snow, and graupel) a Courant-number-independent fluxform Euler-advection scheme (SKAMAROCK, 2006) is employed. This scheme uses the flux formulation of Вотт (1989).

No parameterization of deep convection is applied in the model because it is assumed that the coarser parts of convection can be represented at the implemented scales. However, for the smaller scales of convection a shallow convection scheme based on the mass-flux cumulus parameterization (TIEDTKE, 1989) is used. The application of the scheme is restricted to shallow convection and therefore only concerns clouds with a vertical extension of less than $300 \mathrm{hPa}$. This parameterization describes the sub-grid convective transport of moisture from the boundary layer to mid-levels and is necessary to avoid the overestimation of low cloud coverage

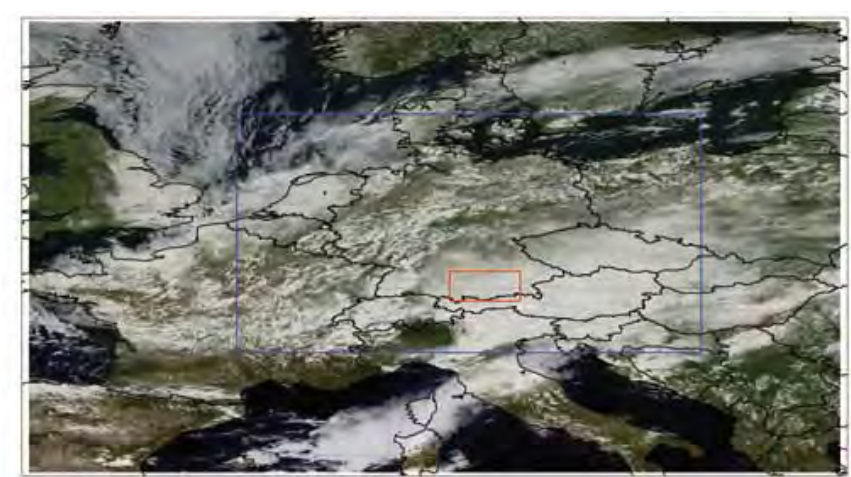

Figure 1: The synoptic situation on August 3, 2006 as seen by the high resolution visible channel of MSG at 12 UTC. The blue and the red boxes depict the domains of the COSMO-DE and the POLDIRAD in Southern Germany.

in certain cases (THEUNERT and SEIFERT, 2006). For explicit simulation of deep convection, a fast sedimenting ice phase hydrometeor type is needed. Therefore the single-moment five-class microphysics scheme was extended to include graupel as a new precipitation class (REINHARDT and SEIFERT, 2006). For graupel an exponential size distribution is assumed with a fixed intercept parameter $\mathrm{N}_{0}$. For the snow size distribution a temperature and mixing-ratio dependent intercept parameter is assumed (FIELD et al., 2005). The raindrop size distribution is assumed as a gamma distribution (ULBRICH, 1983): $N(D)=N_{0} D^{\mu} \exp (-\lambda D)$ with $\mu=0.5$ in COSMO-DE. The slope parameter $\lambda$ is a function of and rain water content. Further features of the physics packages are a seven-level soil model and the possibility to use a three-dimensional turbulence model with the complete metric terms.

COSMO-DE covers the domains of Germany, Switzerland, and Austria with 421 x 461 x 50 grid points (Fig. 1). Initial and boundary conditions are provided by COSMO-EU with $7 \mathrm{~km}$ horizontal resolution, which covers entire Europe. Due to the fact that COSMO-DE has to deliver forecasts earlier than the coarser operational models, these boundary conditions stem from simulation runs which are 3 hours older. Both COSMO models use a nudging scheme for the assimilation of conventional data like radiosonde data, wind profiler, aircraft data (AMDAR), and surface pressure from stations, ship, and buoy. The only remote sensing data considered are radar reflectivities from the German weather radar network. For this purpose latent heat nudging is used in COSMO-DE, which gives a positive impact on precipitation forcast skill up to four hours forecast time (STEPHAN et al., 2008). The model evaluation is carried out on simulations by COSMO-DE (version COSMO 4.0) started at 0 UTC. 


\subsection{Data and methodology}

\subsubsection{SEVIRI}

The high-temporal resolution satellite related analysis is based on observations of the Spinning Enhanced Visible and Infrared Imager (SEVIRI) onboard Meteosat Second Generation (MSG). SEVIRI measures visible (VIS) and thermal infrared (IR) radiation in twelve channels and carries out full disc observations (i.e., within a field of view of approximately $80^{\circ}$ ) every 15 minutes (SCHMETZ et al., 2002). After the calibration process IR radiances are converted to equivalent blackbody or brightness temperatures (BTs). In the IR two channels have been selected for the comparison: the $6.2 \mathrm{~m}$ channel in the water vapor absorption band which can be used to retrieve upper tropospheric water vapor and the $10.8 \mathrm{~m}$ channel in the atmospheric window showing only weak water vapor continuum absorption. The BTs measured in the $10.8 \mathrm{~m}$ channel are highly correlated to the target temperatures. Consequently, this channel is suitable for detecting clouds due to their temperature which is generally lower than the temperature of the surface beneath. The spatial sampling distance of BTs at sub-satellite point is $3 \mathrm{~km} \times 3 \mathrm{~km}$ and increases with distance from sub-satellite point. Over Europe, the north-south sampling distance ranges from 4 to $12 \mathrm{~km}$ resulting in about 5 to $6 \mathrm{~km}$ over Germany. The eastwest sampling distance is about 3 to $4 \mathrm{~km}$ over Germany. Available products are the cloud mask (REUTER et al., 2009), cloud top pressure (CTP), cloud optical thickness (COT), and the life cycle of convective systems (SCHRÖDER et al., 2009). The accuracy of BT observations is specified via the calibration performance of better than $1 \mathrm{~K}$ for all thermal IR channels (SCHMETZ et al., 2002). For products derived from BT observations via complex algorithms it is much more difficult to specify their accuracy. The cloud detection algorithm from FU Berlin has been validated against synoptic measurements and corresponding high spatial resolution observations by the Moderate Resolution Imaging Spectroradiometer (MODIS) satellite instrument as well as LIDAR observations (see detailed description in REUTER et al., 2009). Comparison of MSG to MODIS for several case studies shows correlations of 0.92 and 0.84 for COT and CTP, respectively.

\subsubsection{AMSU}

Temperature and humidity profile information observed by microwave sounders is a key ingredient in the daily assimilation cycles of NWP models. This is one motivation to operate AMSU onboard the polar orbiting satellites NOAA 15-17, AQUA, and METOP. AMSU is a cross-track scanning instrument with a swath width of approximately $2000 \mathrm{~km}$. It is subdivided into two instruments, AMSU-A and AMSU-B. AMSU-B is equipped with two window channels $(89$ and $150 \mathrm{GHz}$ ) and three channels $(183.31 \pm 7,183.31 \pm 3$, and $183.31 \pm 1$
$\mathrm{GHz}$ ) at the water vapor line at $183.31 \mathrm{GHz}$ for water vapor profiling with a $16 \mathrm{~km}$-diameter footprint at nadir. Brightness temperatures have a radiometric accuracy of better than $1.1 \mathrm{~K}$ and absolute calibration should be within $1 \mathrm{~K}$ (SOUNDERS et al., 1995). On METOP, AMSU-B has been replaced by the MHS (Microwave Humidity Sounder). On AQUA, the successor of the AMSU-B has been the HSB (Humidity Sounder for Brazil), omitting the $89 \mathrm{GHz}$ channel. Unfortunately the HSB failed in February 2003. Therefore, there are between four to eight observations per day with higher microwave frequency channels available over the domain of interest.

Observations close to the line center $(183.31 \pm 1$ $\mathrm{GHz}$ ) first of all give an impression of the water vapor distribution in the upper troposphere. In addition, significant scattering at this frequency occurs in strong convective cores with high frozen hydrometeor contents leading to a BT depression. In the $150 \mathrm{GHz}$ window channel, thermal radiation in cloud free conditions mainly stems from water vapor continuum absorption in the boundary layer leading to a minor influence of the surface emissivity. The signal observed at the satellite above precipitation areas composes of radiance emitted by the liquid precipitation and scattering at frozen hydrometeors aloft (BENNARTZ and BAUER, 2003).

\subsubsection{Conventional and polarimetric weather radar}

Over land, radar systems are the key instrument for the observation of precipitation providing information on its spatial and temporal distribution as well as its intensity over large areas. The German radar network consists of $16 \mathrm{C}$-Band radar systems which deliver observations of precipitation over Germany every five minutes. Because the radar reflectivity factor is the sixth moment of the drop size distiribution (DSD) no unique conversion to the rain rate (i.e., roughly the fourth moment) exists. In contrast to conventional radar technology, polarimetric radar systems provide further information on the microphysical properties of the precipitation allowing for enhanced quantitative precipitation estimations. A classification of the predominant hydrometeor type within the observed volume can be derived from the combination of the information content of different polarimetric observables (e. g., Höller et al., 1994; ZRNIC et al., 2001). Therefore, polarimetry gives valuable information for studying issues of cloud microphysical parameterizations. In this study, observations of the differential reflectivity (ZDR) from the polarimetric diversity radar POLDIRAD (SCHROTH et al., 1988) are used, which is operating at C-Band close to Munich. ZDR is a measure of the mean axis ratio and the preferred orientation of non spherical hydrometeors (SELIGA and BRINGI, 1976). Positive values of ZDR are caused by the oblate shape of large raindrops whose major axes are highly oriented horizontally. Negative values of ZDR 
can arise from large oblate hailstones with their major axis aligned around the vertical.

\subsubsection{RANIE product of DWD}

The RANIE product of DWD provides information on accumulated precipitation combining the information content of raingauges and radar observations (T. REICH, Deutscher Wetterdienst, personal communication, 2007). First, precipitation observed by approx. 900 gauges is quality controlled and interpolated by kriging to the $1 \mathrm{~km} \times 1 \mathrm{~km}$ RANIE grid. Second, the same kriging method is applied using the radar data at the gauge stations only. The anomalies between original radar data and this kriging interpolation are then used to modulate the interpolated gauge data on the RANIE grid. Such a combination of ground and remote sensing data of precipitation constitutes the best available product for determining area patterns and total area amounts of precipitation at the ground (e.g., WILSON and BRANDES, 1979). The RANIE product is available four times a day giving the accumulated precipitation during six hours.

\subsection{Summary of the procedure}

The three forward operators are applied to the model simulations taking into account the scattering and sampling characteristics of the different sensors. The observations, except for AMSU, are interpolated to the model grid to facilitate statistical analysis. For AMSU, the simulated BTs are convoluted with the antenna response function (MEIROLD-MAUTNER et al., 2007). As polarimetric radar data are only available from POLDIRAD, SynPolRad will be applied on a smaller subdomain $(86 \mathrm{x}$ 72 grid points) centered over Oberpfaffenhofen (Figure 1). The evaluation is done in terms of BTs from SEVIRI and AMSU and COT retrieved from SEVIRI. CTP is not considered because its determination from model output is rather sensitive to threshold values. Information of the precipitation intensity is provided in terms of reflectivity from the radar network and POLDIRAD. Ground truth is given by the RANIE product.

The evaluation is based on comparisons between the different observations and the simulations at specific times evaluating the spatial distribution of clouds and precipitation as well as the intensity of the synthetic and observed quantities. This is mainly done on an empirical basis comparing both, simulations and observations visually as this is the most intuitive way to demonstrate the information content of every remote sensing instrument and the added value resulting from the synergy of all sensors. Furthermore, statistical information is provided based on classical statistical skill scores as the root mean square error (RMSE), the probability of detection (POD), the frequency bias (FBI), the false alarm ratio (FAR), and the Heidke skill score (HSS; DAMRATH et al., 2000) which measures the fractional improvement of the forecast over the random chance. Furthermore, the fractions skill score (FSS; ROBERTS and LEAN, 2008) is included. The FSS compares observed and forecasted frequencies at subdomains and therefore avoids comparing forecast and observation at the spatial scale of the model gidbox size where precipitation is not deterministically predictable. A perfect forecast has $\mathrm{FSS}=1$ while a forecast without any skill has $\mathrm{FSS}=0$. In this study we choose for the FSS a subdomain size of 21 $\mathrm{x} 21$ COSMO-DE gridpoints.

A general problem in QPF is the representation of the diurnal cycle of convection leading to QPF errors both in magnitude and phase (GUICHARD et al., 2004). Possible time shifts between the model and the observations are identified comparing the observed and synthetic cloud and precipitation products averaged over different domains and represented as a function of time. For the SEVIRI data, the development of convection during the course of the day (for the second case study) is analyzed employing a harmonic analysis (WALTHER et al., 2009). This analysis allows the determination of the minimum of the diurnal cycle of BT at $10.8 \mathrm{~m}$ and the corresponding local solar time on pixel basis. In order to evaluate the life cycle of convection in the model, a tracking algorithm is employed on both, observed and simulated BTs at $10.8 \mathrm{~m}$ (BT10.8). The tracking algorithm uses a BT threshold that is determined case sensitive in a two-step process: first, the time of maximum cold cloud cover is calculated by applying a BT10.8 threshold of 230 $\mathrm{K}$. Second, the ten percentile of BT10.8 at the time of maximum cold cloud cover defines the threshold. In two successive images connected areas with BT10.8 smaller than this threshold are identified, and each area is considered as a cold cloud (or convective system). The assignment of a pair of convective systems mainly relies on the maximum overlap criterion and, applied successively to a series of BT10.8 images, gives the life cycle of convective systems. This procedure allows the identification of merger (two or more systems merge to a single system) and split (a single system resolves into two or more systems) events (for more details see SCHROEDER et al., 2009).

\section{Results}

\subsection{Case August 3, 2006}

The synoptic situation on August 3, 2006 was governed by two low-pressure systems embedded into an upperair trough present during the entire day over Central Europe. One system was located over the North Sea, while the other one was moving slowly along the southern side of the Alps from France to Slovenia. The typical flow pattern during such weather situations in Southeast Germany are northerly winds below 2-4 km and 
Table 1: Categorical skill scores for August 3, 2006 for precipitation exceeding $1 \mathrm{~mm} / 6 \mathrm{~h}$ and $5 \mathrm{~mm} / 6 \mathrm{~h}$ derived for COSMO-DE forecast against RANIE analysis. FBI: frequency bias. POD: probability of detection. FAR: false alarm rate. HSS: Heidke skill score. FSS: fractions skill score for subdomains of $21 \times 21$ gridpoints.

\begin{tabular}{lcccccc}
\hline & \multicolumn{2}{c}{ 00 UTC-06 UTC } & \multicolumn{2}{c}{ 06 UTC-12 UTC } & \multicolumn{2}{c}{ 12 UTC-18 UTC } \\
& $1 \mathrm{~mm} / 6 \mathrm{~h}$ & $5 \mathrm{~mm} / 6 \mathrm{~h}$ & $1 \mathrm{~mm} / 6 \mathrm{~h}$ & $5 \mathrm{~mm} / 6 \mathrm{~h}$ & $1 \mathrm{~mm} / 6 \mathrm{~h}$ & $5 \mathrm{~mm} / 6 \mathrm{~h}$ \\
\hline FBI & 1.69 & 1.02 & 1.08 & 0.98 & 0.97 & 1.25 \\
POD & 0.62 & 0.19 & 0.71 & 0.64 & 0.55 & 0.60 \\
FAR & 0.62 & 0.81 & 0.34 & 0.34 & 0.43 & 0.52 \\
HSS & 0.44 & 0.18 & 0.65 & 0.63 & 0.51 & 0.51 \\
FSS & 0.74 & 0.34 & 0.84 & 0.71 & 0.70 & 0.71 \\
\hline
\end{tabular}

southerly winds above. Warm and humid air is then advected from the Mediterranean Sea around the eastern side of the Alps and lifted by the northern up-sloping flow at low levels. This causes long-lasting continuous rainfall in south-east Germany. Approximately $30 \mathrm{~mm}$ rain were recorded within about 13 hours at Wielenbach $25 \mathrm{~km}$ south of the POLDIRAD instrument. Visible imagery by MSG reveals widespread cloudiness over Germany at 12 UTC (Figure 1).

Observed and simulated precipitation at the ground is compared since this is the quantity of interest to most of the end-users. In case of major differences between observations and simulations, it will be investigated if these differences can be related to differences in the representation of clouds and precipitation in the model. Figure 2 shows the accumulated precipitation during intervals of 6 hours from the RANIE product compared to the corresponding precipitation produced by the COSMO-DE forecast started at 00 UTC. The highest observed precipitation rates are found in Southern Germany where maximum intensities up to $60 \mathrm{~mm} / 6 \mathrm{~h} \mathrm{oc}$ curred in the morning (06-12 UTC). The COSMO-DE reproduces the general spatial distribution and intensity of the precipitation over Germany for the given day relatively well: differences between observed and forecasted domain mean precipitation are less than $20 \%$ for all six-hour intervals (see subtitles in Figure 2). However, a number of regional differences exist. Over Southern Germany, the western part of the precipitation is underestimated in spatial extent while the north-eastern part is overestimated. Apart from this main region of interest, the precipitation from 06 to 12 UTC and 12 to 18 UTC in central and north-west Germany is underestimated and the model simulates non-observed precipitation in southern Saxony from 12 to 18 UTC.

Forecast quality is quantitatively assessed by objective categorical skill scores for two different thresholds, i.e., $1 \mathrm{~mm} / 6 \mathrm{~h}$ indicating light rain and $5 \mathrm{~mm} / 6 \mathrm{~h}$ for heavy rain (Table 1). Except for heavy rain during the early period (00-06 UTC) the skill scores show generally a good forecast skill at least at the $21 \times 21$ gridpoint scale (indicated by FSS $>0.7$ ). The reason for the poorer skill of the early heavy rain is that the small regions of heavy precipitation are captured but not well located in the model simulation (also at the $21 \times 21$ grid point scale, Figure 2). The light rain during the early period is significantly overestimated possibly indicating problems in the initialization of the model.

As the highest precipitation rates occurred in the morning, the following discussion will concentrate on observations and simulations at 11 UTC. The representation of clouds is investigated based on the satellite products. The BTs from SEVIRI for a water vapor channel $(6.2 \mathrm{~m})$ and a window channel $(10.8 \mathrm{~m})$ show a band of warm BTs from France to the Baltic Sea. The BT values of $>235 \mathrm{~K}$ at $6.2 \mathrm{~m}$ indicate that the emission is stemming from relatively low altitudes due to a very dry upper- to mid-troposphere. This large scale feature is correctly predicted in position and strength (Figure 3), as could be expected from the motivation for the selection of the case. On the smaller scale, however, differences occur and are largest at the very low and very high BTs at $10.8 \mathrm{~m}$. The COSMO-DE overestimates the spatial extent of the convective event centered over northeastern Austria. Since this is associated with very cold BTs, the COSMO-DE shows a positive bias in this BT range (Figure 3, bottom, right). At the other end of the $\mathrm{BT}$ range, the COSMO-DE tends to overestimate the amount of lower clouds resulting in a positive bias for high BTs.

SEVIRI observations revealed a large area of high clouds centered over North Austria (Figure 3) connected to the much smaller precipitation system over Southern Germany. AMSU observations are well suited to get a better look into the precipitating system because microwaves are able to penetrate the overlaying cirrus deck. Observations at $150 \mathrm{GHz}$ indeed reveal a more focussed area of low BTs over South-eastern Germany and western Austria (Figure 4). Another area of cold BTs is apparent over the Netherlands. These cold BTs indicate the presence of strongly scattering ice particles like snow or graupel most likely accompanied by precipitation below. The comparison with BTs based on COSMO-DE results shows that the area of lower BTs is smaller and not as intense in terms of BT depression as in the observation. This is an indicator that the model underestimates the area and the intensity of precipitation and especially the presence of ice scatterers. The area of BT depression over the Netherlands is completely nonexistent in the simulation. The lack of frozen hydromete- 


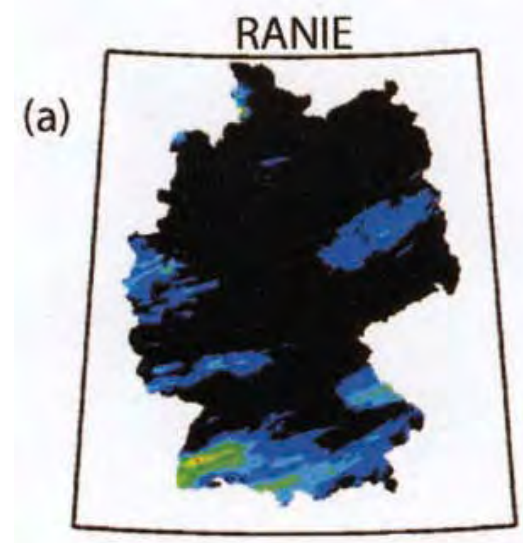

Mean: $0.51 \mathrm{~mm} / 6 \mathrm{~h}$, Max: $52.10 \mathrm{~mm} / 6 \mathrm{~h}$

(b)

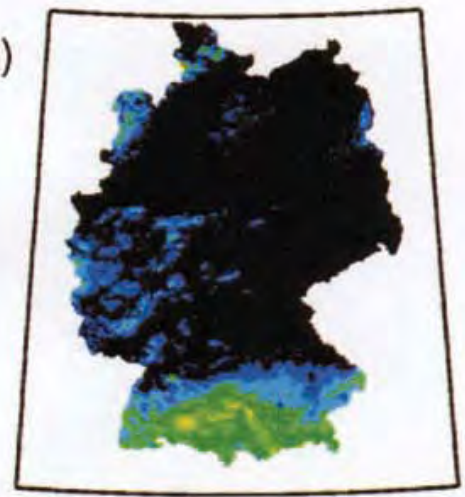

Mean: $1.56 \mathrm{~mm} / 6 \mathrm{~h}$, Max: $67.20 \mathrm{~mm} / 6 \mathrm{~h}$

(c)

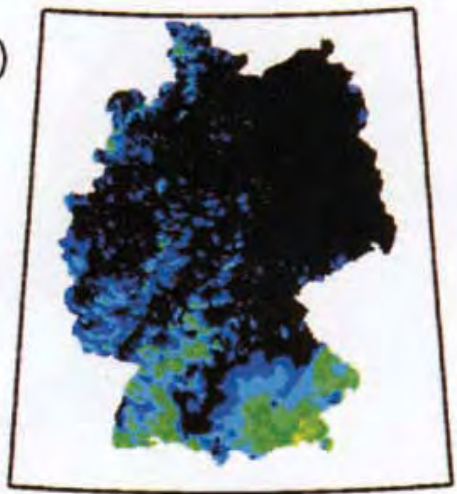

Mean: 1.34 mm/6h, Max: $36.90 \mathrm{~mm} / 6 \mathrm{~h}$

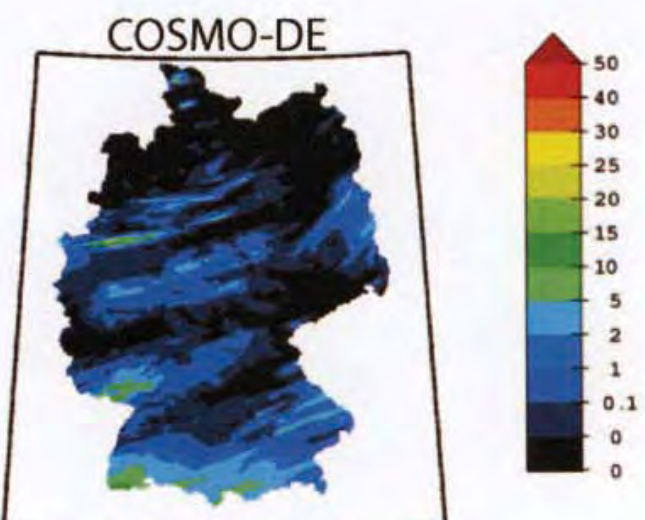

Mean: $0.61 \mathrm{~mm} / 6 \mathrm{~h}$, Max: $27.67 \mathrm{~mm} / 6 \mathrm{~h}$

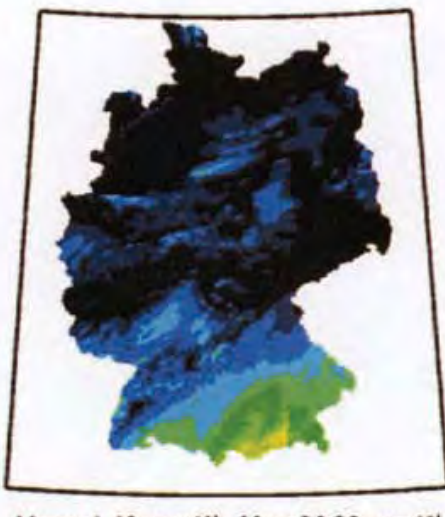

Mean: $1.49 \mathrm{~mm} / 6 \mathrm{~h}, \operatorname{Max}: 30.29 \mathrm{~mm} / 6 \mathrm{~h}$
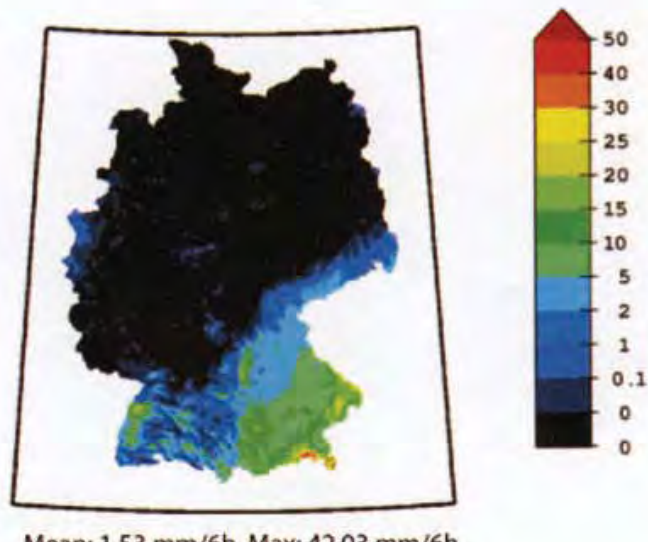

Mean: $1.53 \mathrm{~mm} / 6 \mathrm{~h}$, Max: $42.03 \mathrm{~mm} / 6 \mathrm{~h}$

Figure 2: Comparison of accumulated precipitation at the ground ( $\mathrm{mm} / 6 \mathrm{~h}$ ) for August 3, 2006 from the RANIE precipitation analysis (left column) and COSMO-DE simulations (right column) for (a) 00-6 UTC, (b) 06-12 UTC, and (c) 12-18 UTC.

ors and the related strong scattering most likely explain why the histograms for the BT distribution over land at $150 \mathrm{GHz}$ (Figure 4, bottom, left) show much more pixels without depression through scattering for the simulation than for the observation. This is also manifested in the bias of $3.9 \mathrm{~K}$ which explains, together with slightly misplaced precipitation areas by the model, the RMSE of $13.6 \mathrm{~K}$. The $182.31 \mathrm{GHz}$ observation and simulation agree quite well showing the same band of dry upper tropospheric air mass over North Germany as the $6.2 \mathrm{~m}$ channel (Figure 3). Over the Baltic Sea even warmer BT (less water vapor) is observed than evident in the model which is also shown by the histograms for $182.31 \mathrm{GHz}$ over land.

While AMSU observations provide information on frozen hydrometeors in the upper part of the precipitation system polarimetric, ground-based radar can provide information on the characteristics of the liquid pre- 

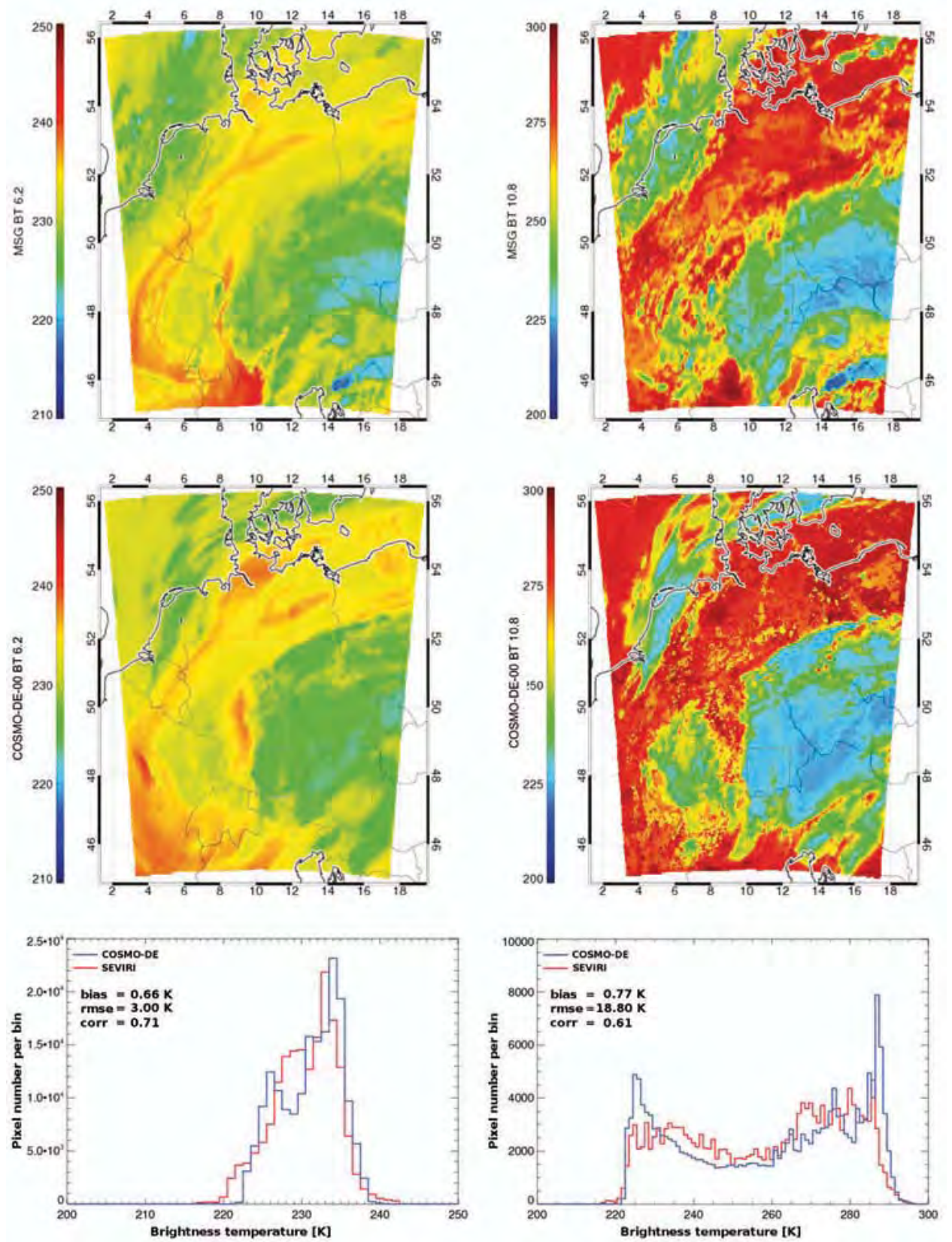

Figure 3: SEVIRI observations (top row) and SynSat simulation from COSMO-DE (middle row) for $6.2 \mathrm{~m}$ (left column) and $10.8 \mathrm{~m}$ channels (right column) at 11 UTC on August 3, 2006. The bottom row shows the corresponding distribution of brightness temperatures for the observations and simulations.

cipitation. Figure 5 shows the observed and synthetic $1^{\circ}$ PPI scans of reflectivity and ZDR for POLDIRAD again at 11 UTC. The observations are dominated by high reflectivities in the order of $30 \mathrm{dBZ}$ in the vicinity of the radar, which are related to moderate rain of about $3 \mathrm{~mm} / \mathrm{h}$. The system becomes weaker with increasing range and no clear brightband structure can be seen in the observations. The brightband caused by melting of ice particles would be expected at a distance slightly closer than that about $1900 \mathrm{~m}$ above ground $(90 \mathrm{~km}$, i.e., $0.8^{\circ}$ latitude and $0.6^{\circ}$ longitude, away from the radar). The COSMO-DE produces higher reflectivities with val- ues exceeding $40 \mathrm{dBZ}$. This overestimation in reflectivity can result from both, an overestimation of precipitation intensity and from the DSD assumed by the microphysical parameterization scheme producing too many large drops. The latter one is due to the fact that reflectivity increases proportional to the sixth power of the diameter which makes it highly sensitive to changes in the DSD.

ZDR is an indicator for the presence and the amount of large oblate raindrops and can therefore be used to specify the drop size distribution of rain due to the well defined relationship between drop size and drop shape. 
AMSU-B
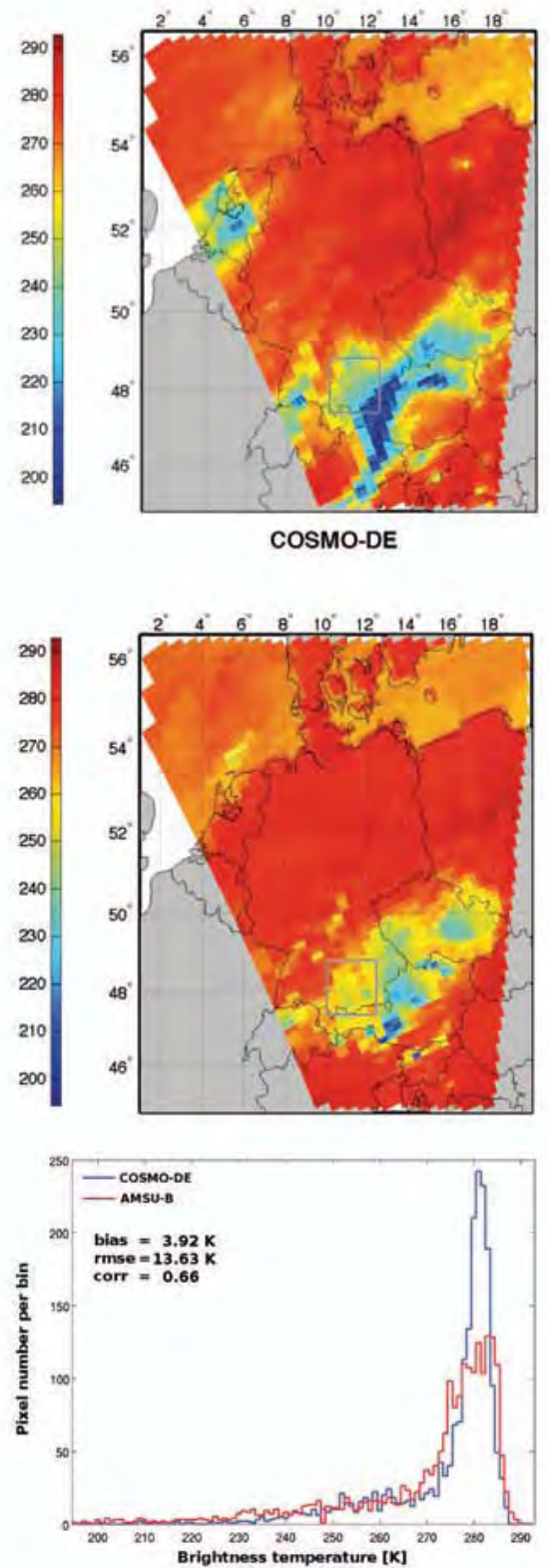

AMSU-B
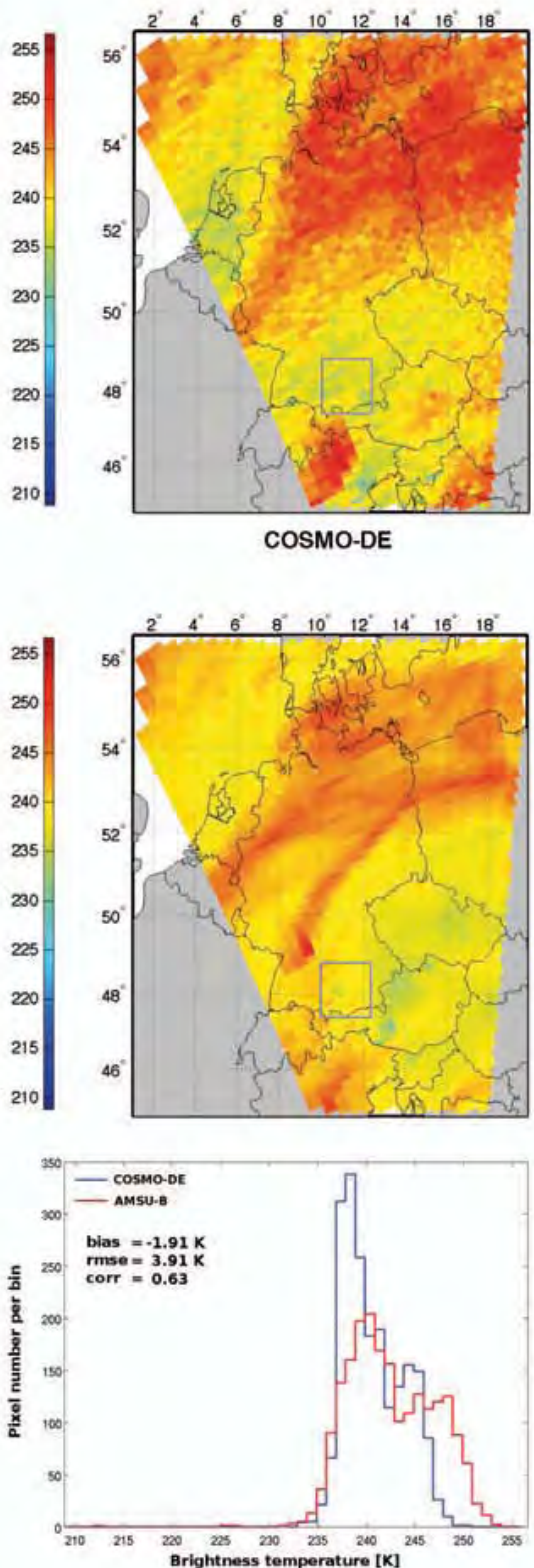

Figure 4: AMSU-B (top) observations and SynSatMic (middle) simulations of brightness temperatures at $150 \mathrm{GHz}$ (left) and $182.31 \mathrm{GHz}$ (right) on August 3, 2006 at 11 UTC. The lower row shows the corresponding distribution of brightness temperatures for the observations and simulations only for land surfaces.

Positive ZDR values represent oblate and horizontally aligned particles while negative values result from scattering at vertically aligned particles. In general, ZDR is positively correlated with $\mathrm{Z}$ as larger raindrops are more oblate and produce a higher $\mathrm{Z}$ and higher ZDR. This correlation can be found both in the observations and in COSMO-DE (Figure 5). In the model it can be seen more clearly due to the fixed form of the DSD. While most of the observed values of ZDR in the region of rain are smaller than 1 , the COSMO-DE produces values larger than 1 almost everywhere in the vicinity of the radar. One explanation for the overestimation of ZDR and, thus, the overestimation of large drops might be the DSD that is broader in the model than the narrow one observed by POLDIRAD in this event. Indeed the COSMO DSD considerable deviates from a classical MarshallPalmer DSD (Marshall and Palmer, 1948; see Figure 6).

In about $50 \mathrm{~km}$ distance from the radar (i.e., $0.5^{\circ}$ latitude and $0.3^{\circ}$ longitude) a ring structure of enhanced ZDR is observed (Figure 5). This is due to the increased dielectric constant of wet oblate snow flakes in the melting layer. ZDR is thus better suited to detect melting layer signatures than $\mathrm{Z}$, which does not reveal the brightband in this case - probably due to the high variations in 

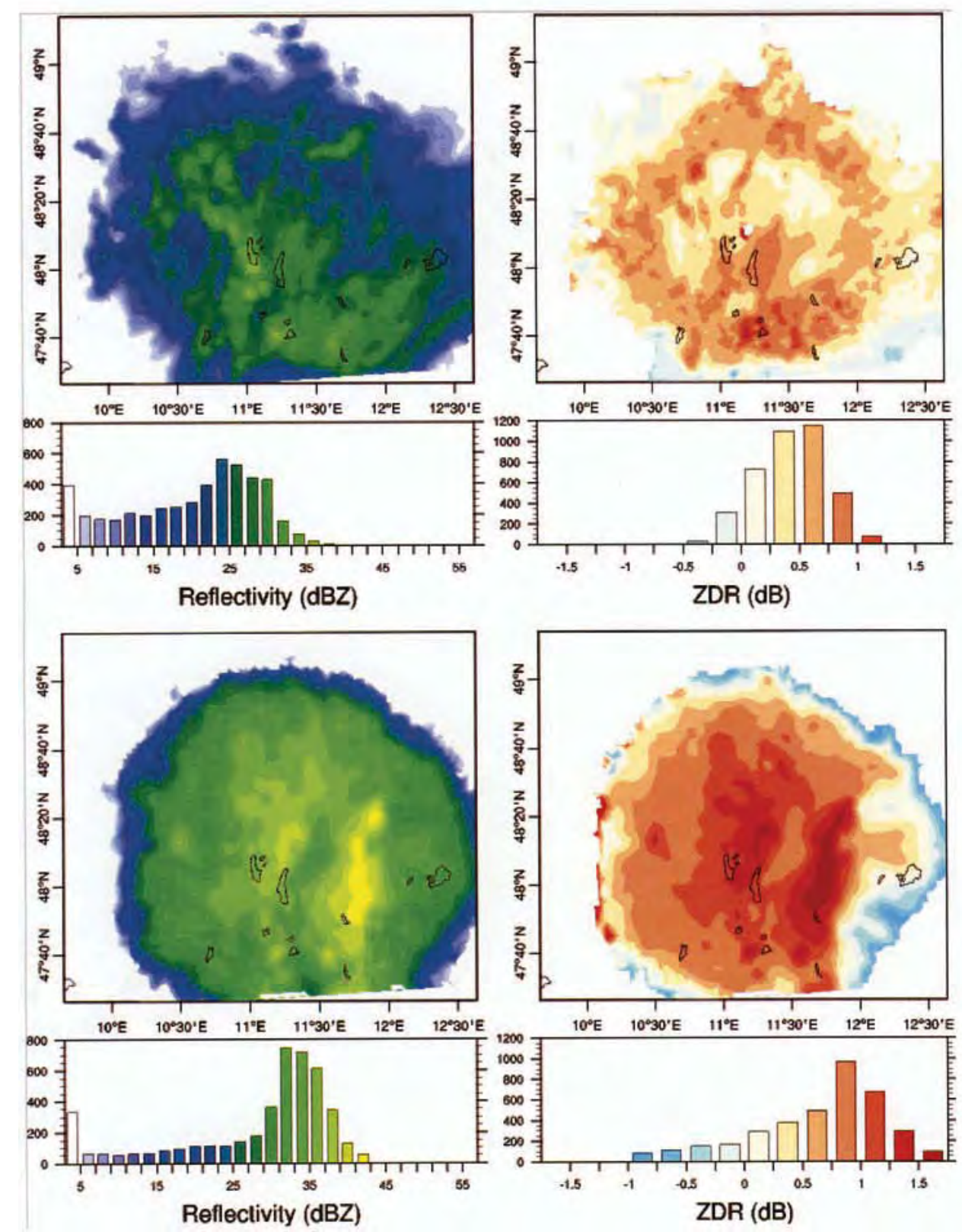

Figure 5: Observed (top row) and simulated (bottom row) $1^{\circ}$ PPI scans of reflectivity (dBZ) (left column) and ZDR (dB) (right colum) of the polarimetric radar POLDIRAD at 11 UTC on August 3, 2006.

$\mathrm{Z}$ and beam broadening at larger distances. The negative ZDR values at far ranges in the simulations can be attributed to vertical aligned ice particles and to differential attenuation by the rain layer. The latter was not as pronounced in the observations as in the simulations.

\subsection{Discussion}

The analysis shows that the COSMO-DE provides a relatively good forecast for August 3, 2006 with some minor problems regarding location, intensity, and timing of regional precipitation events. This day is characterized by two main centers of interest: the precipitation system over the Alps which is underestimated in spatial extent by the model especially regarding its western part and the weaker system over the north-western German coast. The latter is connected to a frontal zone whose high level cloudiness is captured by COSMO-DE (Figure 3) but does not produce the weak precipitation at the ground (approx. $3 \mathrm{~mm} / \mathrm{h}$ ). This might be a boundary effect due to the proximity to the domain boundaries and the prevailing north-westerly flow. For the 11 UTC analysis over the POLDIRAD domain in Southern Germany domain, the different sensors show the following results:

- amount of high clouds is overestimated by COSMODE (SEVIRI),

- the amount of ice scatterers is underestimated by COSMO-DE (AMSU), and 


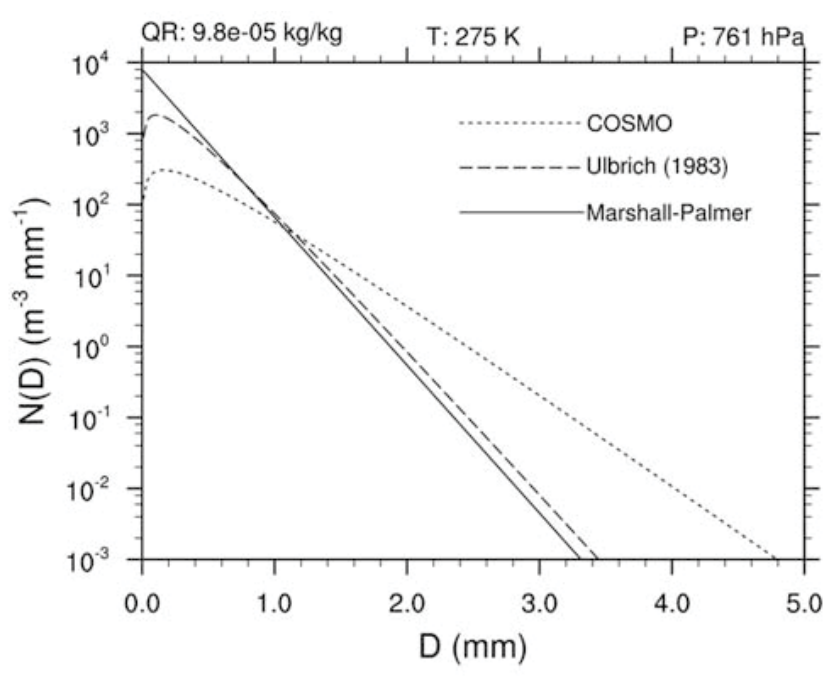

Figure 6: Comparison of the drop size distribution assumed by the COSMO-DE together with the ones proposed by MARSHALL and PALMER (1948) and ULBRICH (1983) valid for a rain mixing ratio of $9.8 \times 10^{-5} \mathrm{~kg} / \mathrm{kg}$ at a temperature of $275 \mathrm{~K}$ and a pressure of 761 $\mathrm{hPa}$.

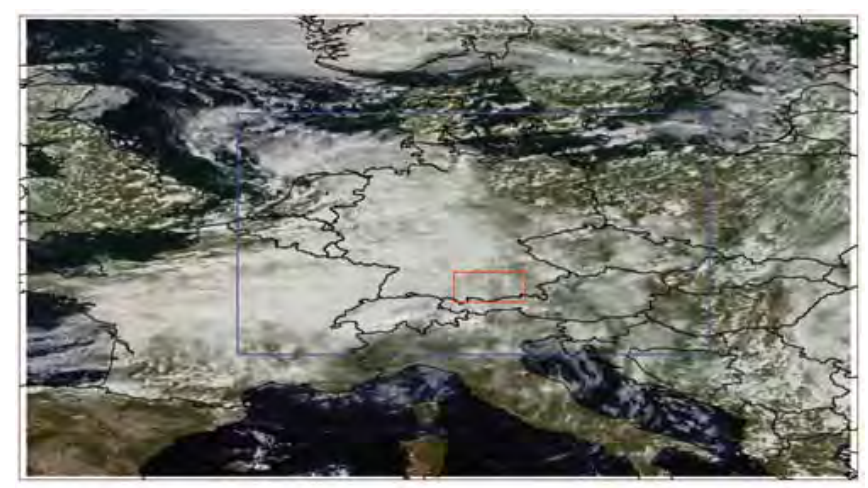

Figure 7: Same as Figure 1 but for August 28, 2006.

- reflectivity in rain is overestimated by COSMO-DE (POLDIRAD).

The simultaneous overestimation of high cloud amount, underestimation of ice scatterers, and overestimation of reflectivity indicate that the COSMO-DE is able to produce large quantities of rain although the vertical extent of the cloud and the ice phase are underrepresented. Further studies are necessary in order to investigate if this a common feature in the COSMO-DE simulations which, in this case, could be related to the parameterization of ice nucleation and/or sedimentation. The high radar reflectivity values can be due to an overestimation of rain intensity as well as due to the assumptions regarding the particle size distribution. Since the DSD is of major importance for the precipitation microphysics controlling falling velocities and evaporation rates, this issue should be studied in more detail and for many events, taking into account that the DSD is highly variable in time and space. A further challenge lies in the difficulty to distinguish between intensity and DSD effects, which might be tackled by sensitivity studies employing different DSD parameters.

\subsection{Case August 28, 2006}

On August 28, 2006, the synoptic situation was dominated by a low pressure system located over Denmark (Figure 7). The associated cold front reached Paris at noon and moved towards the Alps with the strong upper-air north-westerly flow passing Munich at about 20 UTC. With the approach of the cold front, embedded convection developed resulting in a narrow band of strong precipitation. Figure 8 shows the comparison of the RANIE product to the simulations by the COSMODE. In contrast to the previous stratiform case the $6 \mathrm{~h}$ accumulations on August 28, 2006 reveal stripe-like structures in both observation and model, which are caused by the movement of individual convective cells during the accumulation period. This illustrates that COSMO$\mathrm{DE}$ is able to resolve convective systems that are not evident in the $7 \mathrm{~km}$ resolution COSMO-EU with parameterized convection (not shown).

In the early morning, precipitation occurs over Southern Germany which is reproduced in spatial extent by the model, but underestimated in intensity. From 06 to 12 UTC, precipitation intensifies, associated with the cold front entering Germany from the West. The model captures this large scale precipitation but again underestimates intensity in the West. At the same time, significant precipitation occurs in the simulation over Northern Bavaria which is not observed. In the afternoon, the front covers almost entire Germany, and precipitation is present everywhere apart from the very north-east. The highest precipitation sums are found in the early afternoon with rain rates exceeding $30 \mathrm{~mm} / 6 \mathrm{~h}$ for several small nuclei connected to convective activity over Northern Bavaria. Though such strong cores do not occur in the model, COSMO-DE is able to reproduce the widespread precipitation in space and intensity. Precipitation taking place from 12 to 18 UTC is underestimated, with the strongest underestimation occurring in the region of the Black Forest. The corresponding categorical skill scores (Table 2) show high skill (FSS > 0.89 ) for light rain $(1 \mathrm{~mm} / 6 \mathrm{~h}$ threshold $)$. This is even higher than for the stratiform case but can easily be explained by the occurrence of widespread rain over the whole model domain which reduces FAR strongly. Therefore the skill scores for heavy rain $(5 \mathrm{~mm} / 6 \mathrm{~h})$ are more meaningful.

For this convectively active day the diurnal characteristics are of major interest. Figure 9 shows the harmonic analysis method applied to BT10.8 as observed by SEVIRI and modelled by the COSMO-DE. The general patterns of minimum BTs and the corresponding local solar times are similar in both, simulations and observations. The north-west to south-east orientation of areas with the same local solar time and a general increase 
Table 2: As Table 1, but for August 28, 2006.

\begin{tabular}{lcccccc}
\hline & \multicolumn{2}{c}{ 00 UTC-06 UTC } & \multicolumn{2}{c}{ 06 UTC-12 UTC } & \multicolumn{2}{c}{ 12 UTC-18 UTC } \\
& $1 \mathrm{~mm} / 6 \mathrm{~h}$ & $5 \mathrm{~mm} / 6 \mathrm{~h}$ & $1 \mathrm{~mm} / 6 \mathrm{~h}$ & $5 \mathrm{~mm} / 6 \mathrm{~h}$ & $1 \mathrm{~mm} / 6 \mathrm{~h}$ & $5 \mathrm{~mm} / 6 \mathrm{~h}$ \\
\hline FBI & 1.16 & 0.60 & 1.10 & 0.89 & 0.96 & 0.98 \\
POD & 0.72 & 0.14 & 0.81 & 0.34 & 0.91 & 0.67 \\
FAR & 0.38 & 0.75 & 0.26 & 0.61 & 0.05 & 0.30 \\
HSS & 0.62 & 0.16 & 0.70 & 0.30 & 0.87 & 0.59 \\
FSS & 0.89 & 0.35 & 0.90 & 0.54 & 0.97 & 0.91 \\
\hline
\end{tabular}

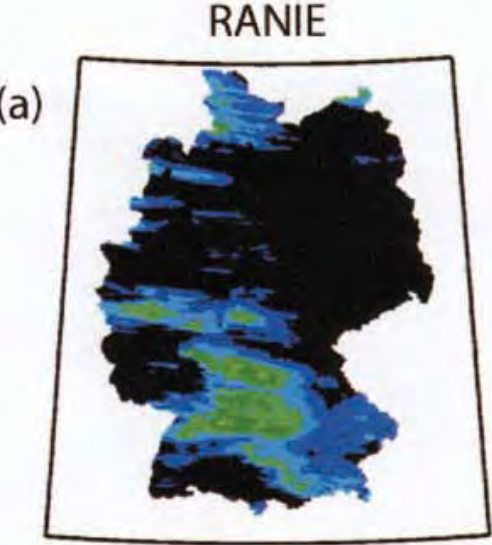

Mean: $1.20 \mathrm{~mm} / 6 \mathrm{~h}$, Max: $24.50 \mathrm{~mm} / 6 \mathrm{~h}$

(b)

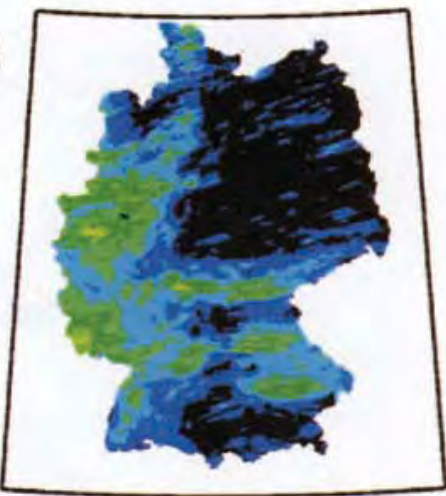

Mean: $2.67 \mathrm{~mm} / 6 \mathrm{~h}$, Max: $30.30 \mathrm{~mm} / 6 \mathrm{~h}$

(c)

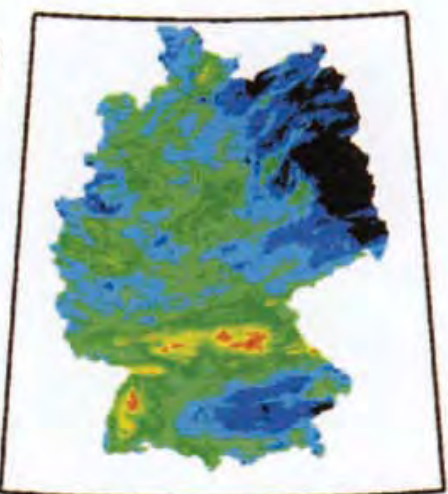

Mean: $6.32 \mathrm{~mm} / 6 \mathrm{~h}$, Max: $48.40 \mathrm{~mm} / 6 \mathrm{~h}$

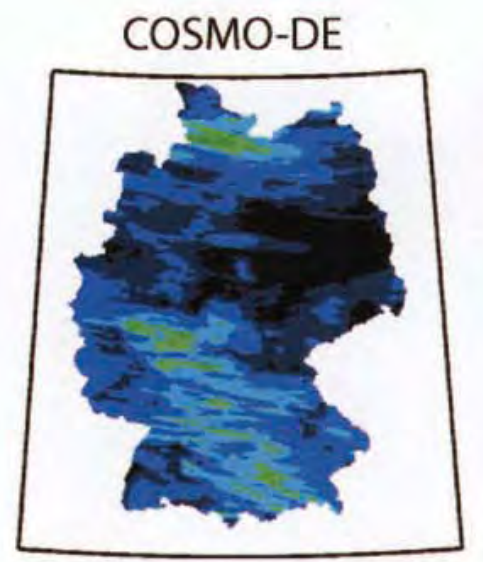

Mean: $1.05 \mathrm{~mm} / 6 \mathrm{~h}$, Max: $20.00 \mathrm{~mm} / 6 \mathrm{~h}$

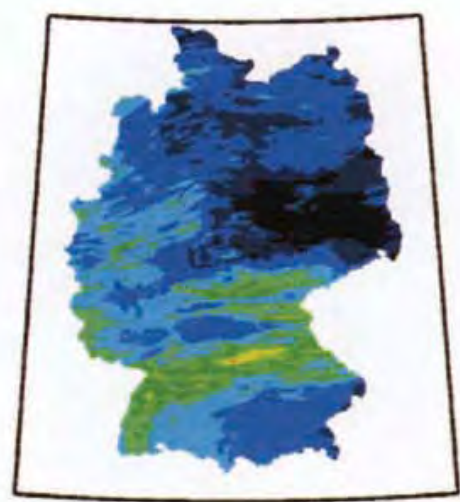

Mean: $2.62 \mathrm{~mm} / 6 \mathrm{~h}$, Max: $30.64 \mathrm{~mm} / 6 \mathrm{~h}$
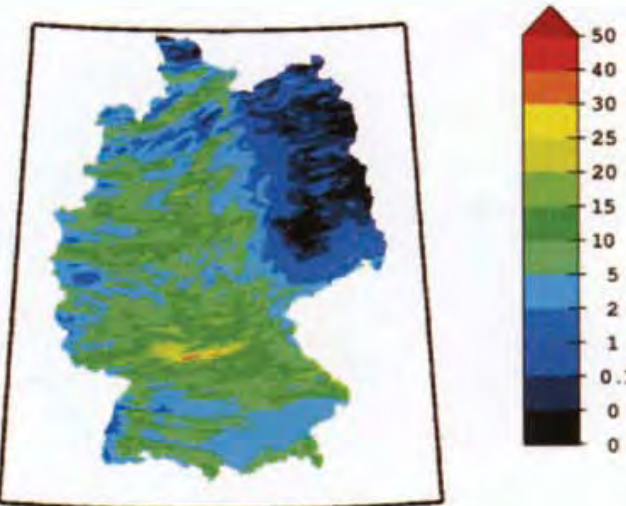

Mean: $5.51 \mathrm{~mm} / 6 \mathrm{~h}$, Max: $35.18 \mathrm{~mm} / 6 \mathrm{~h}$
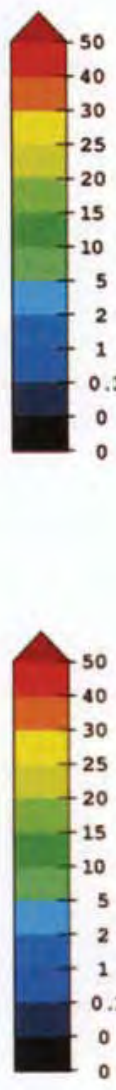

Figure 8: Same as Figure 2 but for August 28, 2006. 

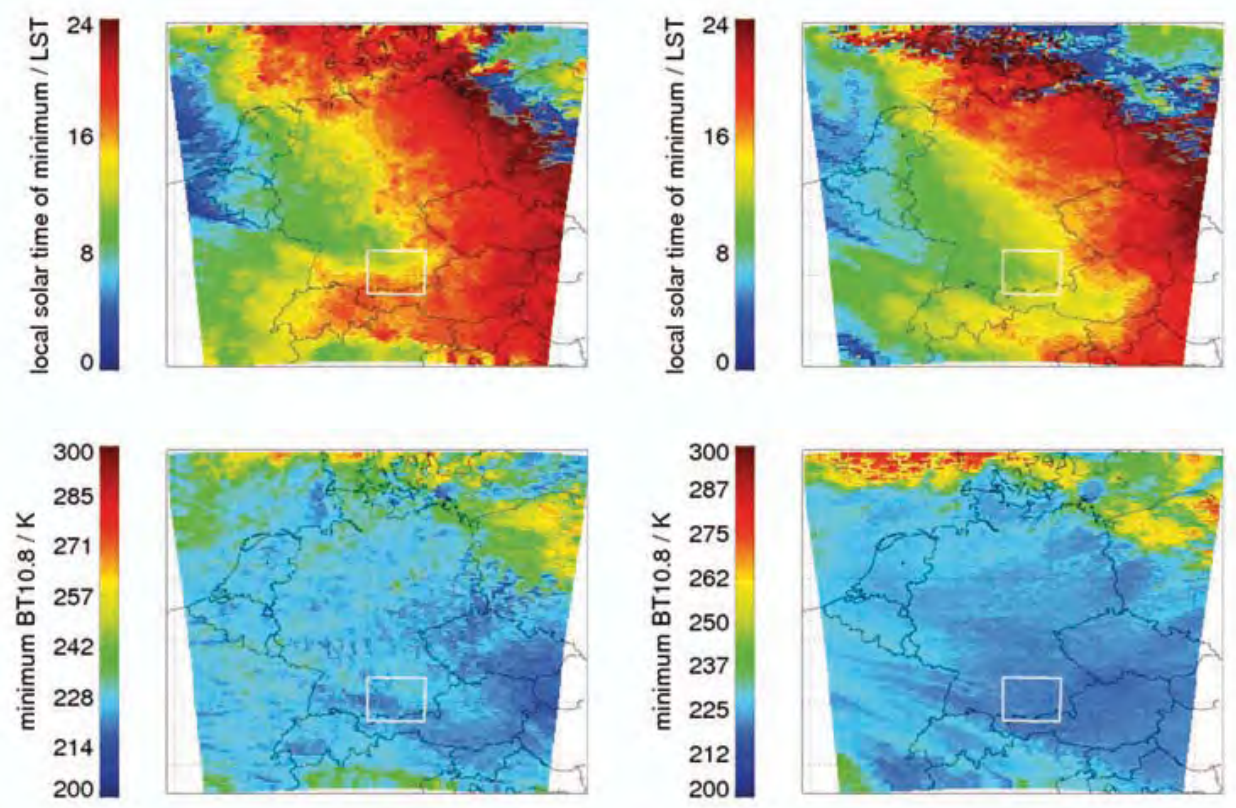

Figure 9: Local solar time of minimum BT10.8 (top row) and corresponding minimum BT10.8 (bottom row) for SEVIRI observations (left column) and COSMO-DE simulations (right column) on August 28, 2006.

Table 3: Start time, duration and maximum area of observed and simulated convective systems shown in Figure 11 on August $28,2006$.

\begin{tabular}{ccccccc}
\hline & \multicolumn{3}{c}{ SEVIRI } & \multicolumn{3}{c}{ COSMO-DE } \\
ID & Start [UTC] & Duration [h] & Max. Area $\left[\mathrm{km}^{2}\right]$ & Start [UTC] & Duration [h] & Max. Area $\left[\mathrm{km}^{2}\right]$ \\
\hline 1 & $15: 00$ & $6: 00$ & 97.200 & $04: 00$ & $3: 30$ & 69.500 \\
2 & $15: 30$ & $8: 30$ & 8.500 & $05: 15$ & $2: 45$ & 9.700 \\
3 & $16: 30$ & $7: 15$ & 28.500 & $06: 00$ & $3: 45$ & 21.200 \\
4 & $16: 30$ & $7: 15$ & 324.400 & $06: 15$ & $14: 45$ & 389.900 \\
5 & $18: 00$ & $5: 45$ & 6.000 & $06: 45$ & $6: 30$ & 78.200 \\
6 & $18: 30$ & $3: 00$ & 5.100 & $18: 00$ & $3: 00$ & 39.700 \\
7 & $20: 15$ & $1: 15$ & 30.300 & & & \\
\hline
\end{tabular}

of local solar time to the east-northeast reflect the general movement of the cold front and associated convective systems. The satellite observations reveal convective fine structure in minimum BT10.8 which is not evident in the model (Figure 9, bottom). This might be explained by an upper layer cirrus deck in the model which is indicated by the widespread region of low BT10.8 centered over Southern Germany. Within the COSMODE simulations, the minimum BTs are reached several hours earlier as compared to the observations, in particular over the western Alps and the POLDIRAD domain.

In order to further analyze the reasons, individual thunderstorms are investigated using the tracking algorithm described in section 2.3. Paths of convective systems for SEVIRI and COSMO-DE were identified from observed and synthetic BT10.8 using tracking algorithms (Figure 10). While all observed convective systems are initiated past 15 UTC, COSMO-DE convection starts much too early with five out of six convective system being formed before 7 UTC (Table 3 ). The convective systems from COSMO-DE mostly start in France and move with the general north-westerly flow. Systems observed by SEVERI start further to the East close to the border of Germany and the Czech Republic and their path exhibits a slight component to the North. COSMODE systems generally show a longer path than observed systems although their lifetime is shorter (Table 3). This might be explained by their connection to the dominant north westerly flow in the morning leading to a quicker movement compared to the systems observed in the late afternoon by SEVIRI.

The observed system 1 (see Figure 10, top) represents the path of the convective system which is closest to the location of POLDIRAD at the time of maximum radar reflectivity. The system is initiated near the frontier between France and Germany at 15 UTC, passing POLDIRAD in the south and dissipating over Southeastern Austria at 21 UTC (i.e., after a life time of 6 hours). The system exhibits continuous area increase until 17:30 UTC and reaches maximum area coverage at 19:45 UTC, after a series of area decrease and increase events. According to MACHADO and LAURENT 
(2004) the maximum in area increase (here at 16:15 UTC) is correlated to maximum rain intensities. Similar to their study the minimum average BT10.8 (here $223 \mathrm{~K}$ ) is reached slightly later (at 17 UTC). Three modelled systems pass the POLDIRAD domain with two of them showing significantly smaller areas and life times than the third system. Both smaller systems dissolved before 10 UTC. Afterwards, the POLDIRAD area is influenced by the significantly larger system 4 that reaches maximum area coverage at 14:30 UTC and minimum BT10.8 of $221 \mathrm{~K}$ already at 09 UTC before it reaches the POLDIRAD area around noon.

The passage of the observed convective system 1 over the POLDIRAD region can also be seen in the diurnal cycle of BTs and cloud parameters (Figure 11). The number of pixels in the lower reflectivity class from 15 $25 \mathrm{dBZ}$ rises steadily until 19 UTC showing the increase in spatial extent of the precipitation event. In the reflectivity class from 25-35 dBZ, this increase is also observed but starts later at 15 UTC and increases slower until reaching its peak value at 18 UTC, marking the intensification of the convective event and the precipitation intensity. In contrast, in the COSMO-DE, the temporal evolution of the precipitation event occurs earlier with maxima at 10:30 and 14:15 UTC for the 15-25 dBZ and the 25-35 dBZ reflectivity classes, respectively. The observations from SEVIRI are consistent with the radar observations. The radar observes maximum precipitation intensities at 19 UTC with a second maximum in the morning. Both precipitation maxima are connected to minima in the SEVIRI brightness temperatures and high cloud optical thickness. While the observations show the classical features of the passage of a convective system (in particular system 1 (Table 3 ) in the late afternoon) with a vertically extended, thick cloud producing surface precipitation, the COSMO-DE forecasts reveal a much weaker relation between the cloud parameters and the precipitation below. Out of the three systems which passed the POLDIRAD domain in the model (Figure 11) only system 4 (Table 3 ) produces a precipitation maximum around noon. However, none of the modelled systems produces a significant signal in the cloud parameters (Figure 12). In general, the model parameters show a rather smooth temporal development which does not agree with the observations. Though differences might be expected due to differences in the spatial and temporal positioning of the convective systems, the interesting result of this comparison is the absence of a strong link between cloud and precipitation parameters in the model.

\subsection{Case discussion}

The synoptic situation of August 28, 2006 was governed by a cold front crossing Germany which triggered convection and postfrontal precipitation. The COSMO-DE is able to produce the front and the related precipitation. However, the model has major problems in reproducing the propagation speed of the system in Southern Germany (Figure 9). The observations suggest that the Alps had a decelerating effect on the cold front which is not reproduced by the model (Figure 9). This might explain why most convective systems over Southern Germany are initiated in the morning by the model in contrast to the observations where convective activity starts in the afternoon. Apart from the differences in the timing of the initialization, the median life time of observed convective systems is larger than the medium life time of those produced by the model. This might be due to differences in dynamical forcing between model and observations, the atmospheric environment being more or less favourable for convective activity. However, this issue can only be addressed in terms of a long-term evaluation in order to prove that the lifetime of convective systems in the COSMO-DE is underestimated.

Apart from the time shift in convective activity, the COSMO-DE has serious problems in representing the daily cycle of cloud parameters over the POLDIRAD domain. In contrast to the observations where the precipitation events are clearly related to the cloud parameters, for the COSMO-DE almost no diurnal cycle is visible in BTs. The COT shows completely contrary behavior to the observations. Further studies should concentrate on studying precipitation intensity and duration of those systems which are underestimated in their vertical extent.

\section{Conclusions}

This paper introduces the QUEST methodology developed to systematically evaluate mesoscale model performance considering the spatial-temporal structure of water in all its three phases. QUEST contributes to the German Priority Program 'Quantitative Precipitation Forecast' by exploiting the potential of remote sensing data currently not used in routine model verification. The information content of this data is used to better understand the water cycle simulated by the model and create a tool to identify processes responsible for the deficiencies in quantitative precipitation forecast.

In contrast to conventional QPF verification measures, this method not only assesses model skill in terms of precipitation at the ground but also compares model clouds and precipitation microphysics to observations. This is done using a variety of multi-dimensional remote sensing observations from radar, satellite, and ground stations to evaluate the model performance in predicting water cycle parameters. Here we apply previously developed forward operators for polarimetric radar (PFEIFER et al., 2008), the infrared (KEIL et al., 2006), and microwave (MECH et al., 2007) spectral range for a tentative evaluation of the COSMO-DE on the basis of two case studies. This model-to-observation approach is favoured since it needs less assumptions compared to the observation-to-model approach. It is illustrated that the 

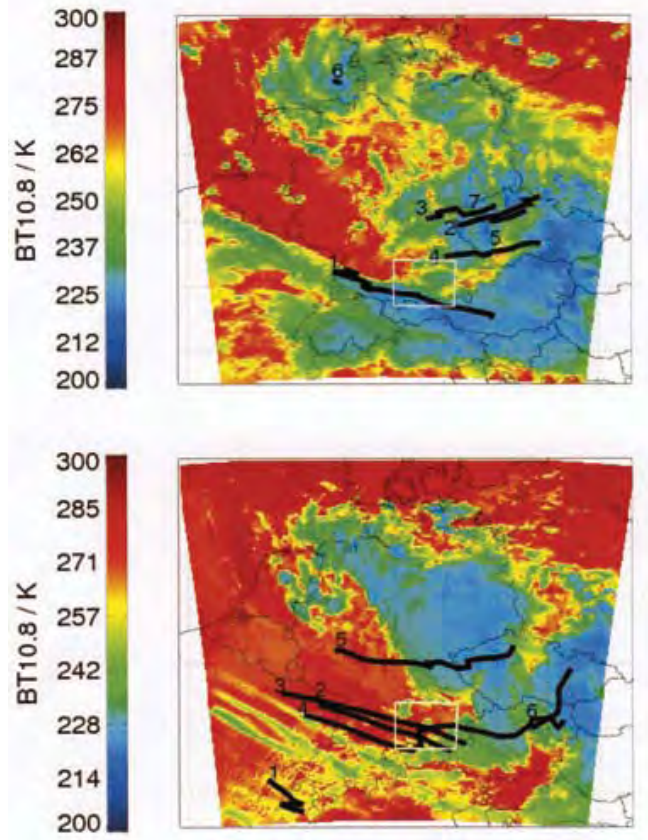

Figure 10: Paths of convective systems observed by SEVIRI (top) and modelled by COSMO-DE (bottom). Background image shows BT10.8 observation and simulation at 21 UTC. All systems with life times larger than three hours and maximum area coverage larger than 200 pixels are plotted. The tracks are numbered according to their starting time. Details of the convective systems are summarized in Table 3.

synergy of these observations can provide information on different parts of precipitation systems including ice clouds, frozen and liquid precipitation.

The analysis of a stratiform precipitation event on August 3, 2006 suggests that the COSMO-DE tends to overestimate the amount of very high clouds (shown by MSG), to underestimate the amount of larger frozen particles (shown by AMSU), and to overestimate radar reflectivity and ZDR (shown by POLDIRAD). To some extent as a consequence of these findings (section 3.2), a new microphysical parameterization is currently under development at DWD. This new scheme will include a two-moment treatment of rain with a more sophisticated parameterization of the raindrop size distribution based on SEIFERT (2008). To address the issues with ice clouds the use of a new parameterizations of ice nucleation is investigated, and the sedimentation of cloud ice as well as the density correction of the fall speeds will be included, which are currently neglected in the COSMO model.

The analysis of convective precipitation event on $\mathrm{Au}-$ gust 28, 2006 highlighted the potential of high temporal and spatial resolution MSG data for investigating the formation and development of convective systems. Though in general a similar number and size of sytems was found in observations and model, the initialization was much to early in the model and seemed to be related to front development affected by the Alps. A system-
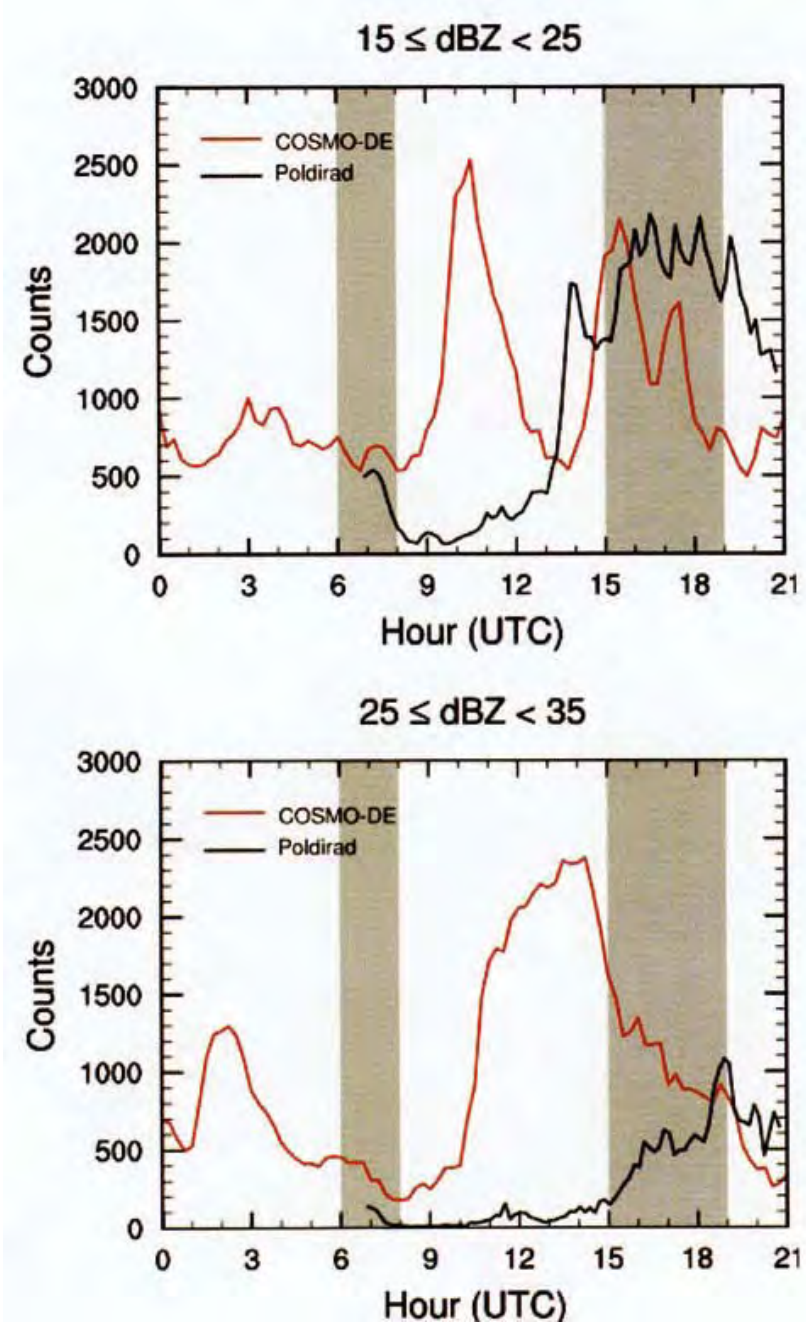

Figure 11: Time series of histograms derived from observed (black) and simulated (red) $1^{\circ}$ PPI scans for reflectivity classes $15-25 \mathrm{dBZ}$ (top) and 25-35 dBZ (bottom) for 28 August 2006 as observed by POLDIRAD and valid for the POLDIRAD domain. The grey shades mark the periods from 6-8 UTC and 15-19 UTC when the two main precipitation events occurred over the POLDIRAD domain (see also Figure 12).

atic long-term evaluation of the three month of the Convective and Orographically-induced Precipitation Study (COPS; WULFMEYER et al., 2008) should focus on the life cycle of convective events and study if these time shifts between observed and simulated convective systems are systematic.

Although this study showed a number of weaknesses in the representation of clouds and precipitation in the COSMO-DE, the results can only be generalized through a systematic long term evaluation. In the future QUEST will focus on the evaluation of the General Observation Period (GOP) 2007 (CREWELL et al., 2008) where additional information by the GPS network will be used to assess the humidity field. The long-term evaluation should point to systematic model deficits by averaging out stochastic errors arising from initial and/or boundary conditions. Furthermore, the long-term 

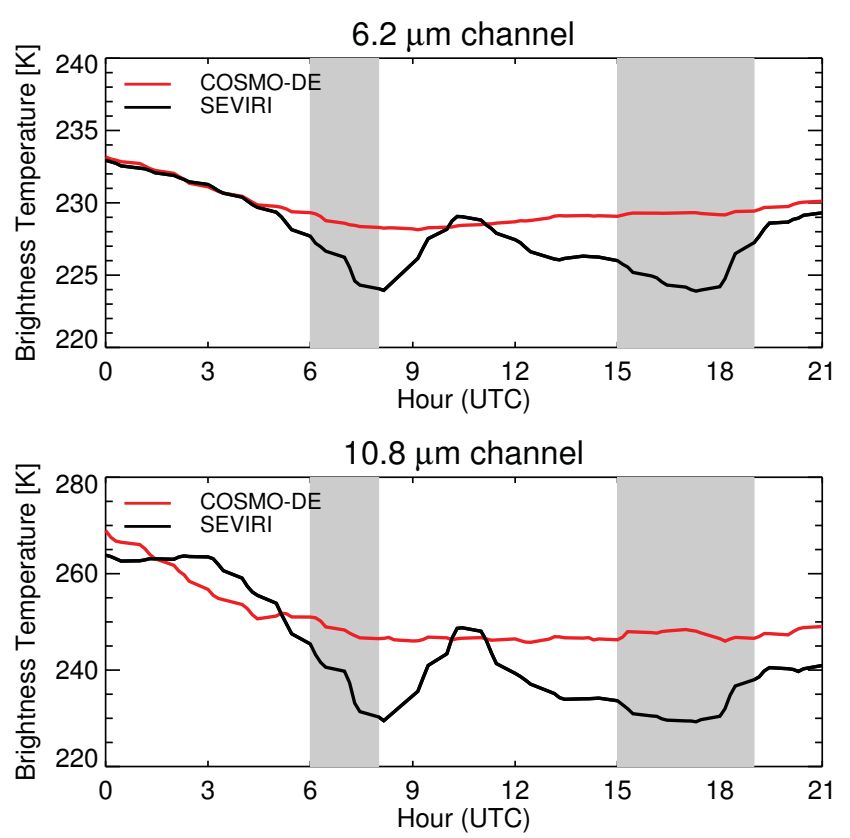

Cloud optical thickness

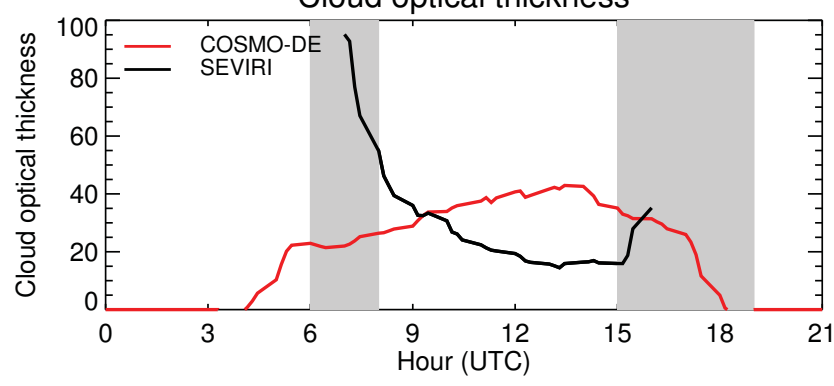

Figure 12: Time series of observed (black) and simulated (red) SEVIRI cloud products for August 28, 2006 averaged over the POLDIRAD domain. From top to bottom: BT 6.2 m, BT 10.8 m, and cloud optical thickness. The grey shades mark the periods from 6-8 UTC and 15-19 UTC where the two main precipitation events occurred over the POLDIRAD domain (see also Figure 11).

evaluation will reveal situations/cases with especially poor/high model performance. The systematic errors already identified for single variables will be crosscorrelated in order to investigate systematic behaviour in the water cycle. Stratification into certain regions and weather situations might help to better isolate deficits. The GOP and COPS observations allow an objective case study selection which will be used to improve microphysical, radiative, and boundary layer parameterizations. These situations can be analyzed in detail by changing model physical parameterizations in order to attribute the errors to the treatment of specific processes: cloud microphysics, convection, radiation, turbulence, evaporation, etc..

\section{Acknowledgments}

This work has been funded by the German Research Foundation within the priority program SPP 1167 Quan- titative Precipitation Forecast under grants BA 3464/12, CR 111/5-2, CR 245/3-2 and FI 435/13-2. We thank Sonja Eikenberg and Stefan Stapelberg for their support with the figures.

\section{References}

Bennartz, B., P. BAUer, 2003: Sensitivity of microwave radiances at $85-183 \mathrm{GHz}$ to precipitating ice particles. Radio Sci. 38, 8075-8082, DOI:10.1029/2002RS002626.

BotT, A., 1989: A Positive Definite Advection Scheme obtained by Nonlinear Renormalization of the Advective Fluxes. - Mon. Wea. Rev. 117, 1006-1015.

Chevallier, F. , P. BAuer, 2003: Model rain and clouds over oceans: Comparison with SSM/I Observations. Mon. Wea. Rev. 131, 1240-1255.

CREwEll, S., M. MECh, T. Reinhardt, C. SElbach, H.-D. BeTZ, E. BROCARD, G. DiCK, E. O'CONNOR, J. Fischer, T. HANisch, T. Hauf, A. HÃNerbein, L. Delobbe, A. Mathes, G. Peters, H. Wernli, M. Wiegner, V. WulfmeYer, 2008: The General Observation Period 2007 within the Priority Program on Quantitative Precipitation Forecasting: Concept and first results. Meteorol. Z. 17, 849-866.

COlle, B.A., M.F. GARVERT, J.B. WOlfe, C.F. MAss, C.P. Woods, 2005: The 13-14 December 2001 IMPROVE-2 event. Part III: Simulated microphysical budgets and sensitivity studies. - J. Atmos. Sci. 62, 3535-3558.

Damrath, U., G. Doms, D. FrÃhwald, E. Heise, B. RICHTER, J. STEPPELER, 2000: Operational quantitative precipitation forecasting at the German Weather Service. - J. Hydrol. 239, 260-285. See also Erratum in J. Hydrol. $247(2001), 264$.

DucrocQ, V., F. BoutTier, S. Malardel, T. MonMerle, Y. SeIty, 2005: The Arome Project. - Houille Blanche-Revue Internationale de L' Eau 2, 39-43.

Ebert, E.E., U. DAMrath, W. Wergen, M.E. BALdWIN, 2003: The WGNE assessment of short-term Quantitative Precipitation Forecast. - Bull. Amer. Meteor. Soc. 84, 481-492.

FIELD, P.R., R.J. Hogan, P.R.A. BROWN, A.J. ILlingWORTh, T.W. ChOularton, R.J. COTTON, 2005: Parametrization of ice-particle size distributions for midlatitude stratiform cloud. - Quart. J. Roy. Meteor. Soc. 131, 1997-2017.

FrITSCH, J.M., R.A. HOUZE JR., R. AdLER, H. Bluestein, L. Bosart, J. Brown, F. CARr, C. DAVIS, R.H. JOHNSON, N. JUNKER, Y.-H. KUO, S. Rutledge, J. Smith, Z. Toth, J.W. Wilson, E. ZIPSER, D. ZRNIC, 1998: Quantitative precipitation forecasting: Report of the eighth prospectus development team, U.S. Weather Research Program. - Bull. Amer. Meteor. Soc. 79, 285-299.

Gallus, JR., W.A., M. Pfeifer, 2008: Intercomparison of simulations using 5 WRF microphysical schemes with dual-polarization data for a German squall line. - Adv. Geosci. 16, 109-116.

Gilmore, M. S., J.M. Straka, E.N. Rasmussen, 2004: Precipitation uncertainty due to variations in precipitation particle parameters within a simple microphysics scheme. - Mon. Wea. Rev. 132, 2610-2627. 
Hense, A., V. Wulfmeyer, 2008: The German Priority Program SPP1167 Quantitative Precipitation Forecast. Meteorol. Z. 17, 703-705.

Höller, H., V.N. BRingi, J. HubBert, M. HAGEN, P.F. MEISCHNER, 1994: Life cycle and precipitation formation in a hybrid-type hailstorm revealed by polarimetric and Doppler radar measurements. - J. Atmos. Sci. 51, 25002522.

Keil, C., A. TAFferner, T. Reinhardt, 2006: Synthetic satellite imagery in the Lokal-Modell. - Atmos. Res. 82, 19-25.

M $\overline{A C H A D O}$, L.A., H. LAURENT, 2004: The convective system area expansion over Amazonia and its relationships with convective system life duration and high-level wind divergence. - Mon. Wea. Rev. 121, 37-49.

MARSHALL, J.S., W.M. PALMER, 1948: The distribution of raindrops with size. - J. Meteorol. 5, 165-166.

Mech, M., S. Crewell, I. Meirold-Mautner, C. PriGENT, J.-P. CHABOUREAU, 2007: Information content of millimeter-wave observations for hydrometeor properties in mid-latitudes. - IEEE T. Geosci. Remote Sens. 45, 2287-2299.

Meirold-Mautner, I., C. Prigent, J.R. PArdo, J.-P. Chaboureau, J.-P. Pinty, M. Mech, S. Crewell, 2007: Radiative transfer simulations using mesoscale cloud model outputs: comparisons with passive microwave and infrared satellite observations for mid-latitudes. - J. Atmos. Sci. 64, 550-1568.

Pfeifer, M., G. Craig, M. Hagen, C. Keil, 2008: A polarimetric radar forward operator for model evaluation. - J. Appl. Meteor. Climatol. 47, 3202-3220.

ReInhardT, T., A. SEIFERT, 2006: A three-category ice scheme for LMK. - COSMO-Newsletter 6, 115-120.

Reuter, M., W. Thomas, P. Albert, M. Lockhoff, R. Weber, K.-G. KARlsson, J. Fischer, 2009: The CM-SAF and FUB cloud detection schemes for SEVIRI: Validation with synoptic data and initial comparison with MODIS and CALIPSO. - J. Appl. Meteor. Climatol. 48, 301-316, DOI: 10.1175/2008JAMC1982.1.

Roberts, N.M., H.W. LEAN, 2008: Scale-selective verification of rainfall accumulations from high-resolution forecasts of convective events. - Mon. Wea. Rev. 136, 78-96.

Schmetz, J., P. Pili, S. TJEMKES, D. Just, J. KERKMANN, S. Rota, A. RATiER, 2002: An introduction to Meteosat Second Generation (MSG). - Bull. Amer. Meteor. Soc. 83, 977-992.

SCHRÖDER, M., M. KÖNIG, J. SCHMETZ, 2009: Deep convection observed from SEVIRI onboard Meteosat-8: Spatial distribution and temporal evolution over Africa in summer and winter 2006. - J. Geophys. Res. 114, D05109, DOI:10.1029/2008JD010653.

SCHROTh, A.C., M.S. CHANDRA, P.F. MEISCHNER, 1988: A C-Band Coherent Polarimetric Radar for Propagation and Cloud Physics Research. - J. Atmos. Oceanic Technol. 5, 804-822.

SEIFERT, A., 2008: A revised cloud microphysical parameterization for COSMO-LME. - COSMO Newsletter 7, 2528.

SEligA, T.A., V.N. BRINGI, 1976: Potential use of radar differential reflectivity measurements at orthogonal polarizations for measuring precipitation. - J. Appl. Meteor. 15, 69-76.
SKAMAROCK, W.C., 2006: Positive-definite and Monotonic Limiters for Unrestricted-Time-Step Transport Schemes. Mon. Wea. Rev. 134, 2241-2250.

SKAMAROCK, W.C., J.B. KLEMP, 2008: A time-split nonhydrostatic atmospheric model for weather research and forecasting applications. - J. Comput. Phys. 227, 34653485, DOI:10.1016/j.jcp.2007.01.037.

Sounders, R.W., T.J. Hewison, S.J. Stringer, N.C. ATKINSON, 1995: The radiometric characterization of AMSU-B. - IEEE Trans. Microwave Theory Tech. 43, 760-771.

StEPHAN, K., S. KLINK, C. SCHRAFF, 2008: Assimilation of radar-derived rain rates into the convective-scale model COSMO-DE at DWD. - Quart. J. Roy. Meteor. Soc. 134, 1315-1326.

StePPELER, J., G. DOMS, U. SCHÜtTLER, H. W. BITZER, A. Gassmann, U. Damrath, G. Gregoric, 2003: Meso-gamma scale forecasts using the nonhydrostatic model LM. - Meteor. Atmos. Phys. 82, 75-96.

Stoelinga, M.T., P.V. HobBS, C.F. MASS, J.D. LoCAtelli, B.A. Collie, R.A. Houze, A.L. Rangno, N.A. Bond, B.F. SMull, R.M. Rasmussen, G. Thompson, B.R. Colman, 2003: Improvement of microphysical parameterization through observational verification experiment. - Bull. Amer. Meteor. Soc. 84, 18071826.

Theunert, F., A. SeIfert, 2006: Simulation studies of shallow convection with the convection-resolving version of the DWD Lokal-Modell. - COSMO-Newsletter 6, 121128.

TiEdTKE, M., 1989: A comprehensive mass flux scheme for cumulus parameterization in large-scale models. - Mon. Wea. Rev. 117, 1779-1800.

ULBRICH, C.W., 1983: Natural variations in the analytical form of the raindrop size distribution. - J. Appl. Meteor. Climatol. 22, 1764-1775.

WAlther, A., M. Schröder, J. Fischer, R. Bennartz, 2009: Comparison of precipitation in the regional climate model BALTIMOS to radar observations. - Theor. Appl. Climatol., published online, DOI:10.1007/s00704009-0174-1.

WiCKER, L.J., W.C. SKamarock, 2002: Time Splitting Methods for Elastic Models using Forward Time Schemes. - Mon. Weather Rev. 130, 2088-2097.

WiLSON, J.W., E.A. BRANDES, 1979: Radar measurement of rainfall - a summary. - Bull. Amer. Meteor. Soc. 60, 1048-1058.

WUlfMEYER, V., A. Behrendt, H.-S. BAuer, C. Kottmeier, U. Corsmeier, G. Adrian, A. Blyth, G. Craig, U. Schumann, M. Hagen, S. Crewell, P. Di Girolamo, C. Flamant, M. Miller, A. Montani, S. Mobbs, E. Richard, M. RotaCh, M. ARPAGAus, H. RusschenberG, P. SCHLÜSSEl, M. KÖNIG, V. GÄrtner, R. Steinacker, M. DORninger, D.D. Turner, T. WeCKWERTh, A. Hense, C. Simmer, 2008: Research Campaign: The Convective and Orographically induced Precipitation Study: A Research and Development Project of the World Weather Research Program for Improving Quantitative Precipitation Forecasting in Lowmountain Regions. - Bull. Amer. Meteor. Soc. 89, 14771486, DOI:10.1175/2008BAMS2367.1.

ZRNiC, D.S., A. RYZHKOV, J. STRAKA, Y. LIU, J. VIVEKANANADAN, 2001: Testing a procedure for automatic classification of hydrometeor types. - J. Atmos. Oceanic. Technol. 18, 892-913. 